\title{
The Mystic Ark: Hugh of Saint Victor, Art, and Thought in the Twelfth Century
}

Review Number: 1710

Publish date: Thursday, 15 January, 2015

Author: Conrad Rudolph

ISBN: 9781107037052

Date of Publication: 2014

Price: $£ 75.00$

Pages: 626pp.

Publisher: Cambridge University Press

Publisher url: http://www.cambridge.org/gb/academic/subjects/history/history-ideas-and-intellectual-history/mystic hugh-saint-victor-art-and-thought-twelfth-century

Place of Publication: Cambridge

Reviewer: Karl Kinsella

In a time of prolific and revolutionary authors Hugh of Saint Victor lit up the 12th century with a particularly unique voice, combining an intense passion for teaching with a pragmatic and systematic mind. Out of his large body of work his Mystic Ark has always provided more questions than answers. In it Hugh describes how one draws a large two-dimensional image of Noah's ark, the world, and Christ who stands above everything, and all acting as a pedagogic and meditative tool for those who follow Hugh's instructions to the letter. The problem with Hugh's description is that frequently it makes little obvious sense, moving from literal to anagogical expressions of meaning which run parallel with often baffling descriptions of what the reader should draw. Even mundane matters such as on what it should be drawn are not clear because the description requires an image so immense that depicting the Ark on parchment would have been at the very least impractical, but more likely, impossible. These obstacles are compounded due to the fact that there are no surviving examples or fragments of the drawings of which we know. Rudolph boldly stands up to these problems, and attacks the image head-on; after many years considering Hugh's description and the drawing itself, Rudolph has shed light on this enigmatic, but popular medieval work. Such a daunting task must be commended, and Rudolph has, for the most part, produced an important book which significantly enhances our knowledge of 12th-century thought, and the Ark's place in it.

There are two main divisions in Rudolph's work, the first comprises a lengthy commentary on The Mystic Ark, and its place within Hugh's Victorine theology; the second offers an English translation of this notoriously difficult Latin text. The commentary is split into three parts, an introduction, a discussion of the four types of Arks Hugh discusses, and a broad conclusion which attempts to make connections between Hugh's systematic approach and wider development in the 12th-century world. Tying the entire book together are a large number of figures illustrating Rudolph's complete re-creation of the Ark which appears in black and white as well as colour plates. I found some colour images a little blurry and the detail difficult to make out, but Rudolph provides a website address with a collection of .zip files of the images which can be downloaded and examined in detail.

The commentary's introduction is relatively brief and fails to spell out assumptions Rudolph makes 
throughout this particular work. For example, Rudolph refers to the Ark text as a reportatio, as a set of student lecture notes which have been worked up in detail subsequent to Hugh's actual lecture. The argument for this assertion can be found in Rudolph's 2004 work on The Mystic Ark, where he explains the matter in persuasive detail.(1) This earlier work was written as an introduction to the commentary, but it is frustrating to be presented with such a detailed overview of Hugh's text without ready access to the some of the fundamental arguments which define much of Rudolph's current work (p. 503). This, in itself, is not necessarily a problem, but it is a frustrating facet to be faced with at the very beginning, and one feels like one is not getting the full picture. What is contained in the introduction is a useful overview of scholarly theories of The Mystic Ark's purpose. Rudolph offers an excellent response to modern criticism, focusing especially on the mnemonic qualities which have been thought to be found in the work. He frames Hugh's theological and pedagogical output as a middle road between the 'old theology' of monasticism, characterised by the work of Bernard of Clairvaux, and 'new theology's' highly vocal proponents, such as Peter Abelard. Hugh's middle way is characterised by a willingness to conjure innovative solutions to theological problems based on the works of the Church Fathers. Setting The Mystic Ark in this way works very well, linking the Victorine system of exegesis and use of images with their place in the wider frame of 12th-century theological developments. Rudolph is able to explain Hugh's own talent for communicating his thoughts in a visual medium, and partly explains why he used such an ingenious combination of lecture and image to describe his systematic concept of creation and salvation.

The large middle chapter comprises the majority of the commentary. The chapter is more than a simple enumeration of Hugh's sources, although that information becomes clear over the course of the book, it is a discourse on Hugh's theology and exegetical thought. The ark image, as it is described and commented upon in the Mystic Ark text in fact contains four arks, the literal Ark of Noah, the allegorical Ark of the Church, the anagogical Ark of Wisdom, and the tropological Ark of Mother Grace. Rudolph uses this quadripartite structure to organise his own work by focusing on one ark at a time. The Ark reflects a systematic outline of Hugh's extensive thought; the complicated nature of the drawing means Rudolph is forced to provide an almost complete description of Hugh's theology. A task Rudolph admits to be daunting, but manages to do so with great efficiency and clarity.

The discussion of the literal Ark of Noah provides an important starting point to understand the development of the ark theme throughout Hugh's work. The Ark provides a schematic overview of the entirety of creation, with roundels containing images of the six days of creation in the eastern part of the Ark (i.e., at the top of the image), moving westward (i.e., downwards) through to the period described in the Old Testament, the prophets and the exodus of the Israelites. At the centre lies the central cubit, a small square containing a picture of a lamb and an alpha and omega, embodying both Christ and Jerusalem, which forms the centre point around which history revolves. The bottom half of the Ark is concerned with the period of the New Testament, and onward to the Middle Ages, demonstrated by an ordered list of popes in that section. This temporal structure is supported by an imago mundi on which the ark is placed, one which interacts with the temporal events of the ark schematic, especially in the eastern section. Some elements which traditionally appeared in representations of the Ark do not appear in Hugh's description, and he even includes parts which are not mentioned in scripture. Rudolph highlights such contradictions and uses them to emphasise the complicated nature of Hugh's historical exegesis, which Hugh prioritises only in so far as it supports subsequent allegorical and tropological commentary. Such a close reading casts a sense of doubt on Hugh's own assertion, albeit elsewhere, that the historical understanding of scripture is vital, acting as a foundation to all subsequent readings. It would seem, from Rudolph's analysis that, while Hugh's additions and interpretations of the Ark's appearance are not unprecedented, they are unusual and perhaps indicate that Hugh's prioritisation of the historical sense is not as consistent as previously thought. Rudolph's discoveries provide fascinating insight into the interaction of exegetical approaches in both Hugh's work as well as later Victorine authors, and in the process casts new light on Hugh's concept of history, a field which has already invited scholarly attention. $\underline{(2)}$

In relation to the Ark of Wisdom Rudolph discusses different elements of the drawing and their allegorical meaning, the richest discussion in this section relates to the central cubit, which holds a host of meanings. 
From the top left and right hand corners two 'planks' are placed which extend diagonally to the central cubit; each signifying the Israelites and the Gentiles, which eventually come together at the central point in time. This 'plank' system forms one part of an immensely complicated allegorical structure, which Rudolph is able to interpret sensibly. The central cubit embodies the Incarnation, the geographical location of Jerusalem at the centre of the world, as well as the entire cosmos. As if this wasn't enough, we must also conceive of the Ark, and the central cubit as the top of a vertical (three-dimensional) structure, which contains a different, but complementary set of meanings as one moves through the levels. Rudolph consistently reiterates Hugh's insistence on moving the exegetical quality of the image an extra step, one part of which would have been communicated via The Moral Ark, a text by Hugh which often accompanies The Mystic Ark in manuscripts. In a sense it is possible to read Rudolph's work on the Ark of Wisdom as an attempt to recreate the lectures in which the Ark would have been the focus, likening them to modern seminars. This approach provides the sitz im leben for the Ark as a pedagogical and theological tool, one in which the obscure meanings contained in the image could be teased out by the lecturer. The result is a useful exercise when considering both the dissemination of the text and its purpose within a monastic or ecclesiastical setting. There are times where it would seem Hugh's lecture is probably impossible to accurately recreate, and Rudolph's attempt to fill these holes may not always be convincing, but this kind of approach to the matter is certainly worthwhile.

A highlight is Rudolph's discussion of the Ark of Mother Grace, which relates to the level of tropology, or the moral dimension of scripture. Hugh conveys this Ark by means of a series of steps between virtues which are depicted in another set of 'planks'. The relationship between these virtues is, at first glance, difficult to consolidate into a coherent theological and moral framework. Rudolph manages to do so effectively, guiding the reader by using both the colour images as well as the schematic outline he provides. At this point, and possibly earlier in the commentary, an interesting dynamic becomes apparent. Hugh's complicated system of relationships between parts of his systematic theology make it difficult to follow the sense of Rudolph's text sometimes. Rudolph frequently refers his reader back to his re-created image of the Ark, pointing out how Hugh visually constructs these relationships. The result is that the Ark, and the details taken out from it by Rudolph, become an indispensable tool for understanding Hugh's theology, as well as Rudolph's commentary. The pedagogical purpose behind the image, integral to its creation and success during the 12th and 13th centuries, becomes replicated in the process of reading Rudolph's work. I found myself turning to the image consistently, as Hugh refers to it frequently in his text, using it to explain particularly difficult aspects, offering visual clues to the meaning and to a comprehensive Victorine philosophy. In this way the book becomes more than an overview of the Ark's influences and legacy, but a pedagogical tool which indirectly assumes its original role as the focus of a lecture and discussion, with the modern reader taking on the role of Hugh's student. Whether Rudolph intended this dynamic to occur to the modern reader is probably irrelevant, but was a fascinating parallel to the action of reading the work.

The final part of Rudolph's work is a new English translation of The Mystic Ark. This is the second such translation available, the first appearing as part of set of translations which focus on mnemonic texts.(3) Rudolph criticises this translation in the strongest of terms, writing that it 'cannot be used for scholarly purposes,' thus making the case for his own work (p. 380). Such criticism is supported by notes detailing each of the problems he has with the text, which perhaps overstate the point. Rudolph's translation provides an important tool for scholars and is accompanied by a detailed commentary which takes up much of the page space. Patrice Sicard's critical edition of the text is used as the source for the translation, and the corresponding page numbers are given in the margins, making for easy crosschecking. One interesting addition is Rudolph's insertion of a brief discussion of the process of making the image and the decisions which lay behind its appearance. For example, the maiestas figure is taken from the Hortus deliciarum, which would have been contemporary with Hugh's Ark schematic. Throughout the recreated Ark various elements have been taken from $12^{\text {th }}$-century images, which have been cut, processed and pasted into the Ark. I think this is a largely successful decision, although it may have been useful to provide an image of Richard of St. Victor's drawings for his commentary on Ezekiel, although Rudolph does mention them (p. 75). Richard uses almost exactly the same vocabulary as Hugh does to describe his images, as well as an 
almost identical criticism of the plan format being unable to represent certain details. It would seem that Richard's drawings must be in some way modelled on Hugh's work, and may have provided some context of the formal characteristics of Hugh's drawing. However, it is clear that Rudolph's recreation itself is the best and most informative to date, and rewards the patient viewer.

Much like the lack of discussion of The Mystic Ark as reportatio any problems I have of this work is due my desire for more content and detail. For example, Rudolph's framing of Hugh's work places it between monastic theology, and the growing strength of the schools and cathedrals as the setting for a particular type of education. Rudolph evokes this context, especially to argue that particular aspects of Hugh's theology are in direct confrontation to Peter Abelard's logic-based approach. This may certainly be the case, but the presence of Hugh's argument within such a highly popular image raises questions regarding the polemical qualities the image may have had; does adoption of the image mean implicit acceptance of Hugh's arguments? The question remains unanswered. However the real usefulness of Rudolph's work lies in the ability to ask new questions of The Mystic Ark and base any answers on a thoroughly worked out and thoughtful piece of scholarship. This desire for more content is probably unfair, but simply reflects the fascinating nature of Hugh's work which Rudolph has brought to life. Rudolph's book is already quite large and adding more content would certainly have made its structure unwieldy and its size unmanageable. The final word on Hugh's Mystic Ark has probably not been said, but Rudolph has ensured that if it is ever uttered we will owe a huge debt to his painstaking research.

\section{Notes}

1. Conrad Rudolph, First, I Find the Center Point: Reading the Text of Hugh of Saint Victor's The Mystic Ark (Philadelphia, PA, 2004).Back to (1)

2. For example, Franklin Harkins, Reading and the Work of Restoration: History and Scripture in the Theology of Hugh of St. Victor (Toronto, 2009).Back to (2)

3. Found in The Medieval Craft of Memory: An Anthology of Texts and Pictures, ed. Mary Carruthers and Jan M. Ziolkowski (Philadelphia, PA, 2004), pp. 41-70. Back to (3)

Source URL:https://reviews.history.ac.uk/review/1710

\section{Links}

[1] https://reviews.history.ac.uk/item/107270 